\title{
A User-Centered Design Approach to Develop a Web-Based Instructional Resource System for Homeland Education
}

\author{
Chaoyun Liang* \\ Department of Information Communication, College of Informatics, \\ Yuan Ze University, 135 Yuan-Tung Rd., Chung-Li, Taoyuan, 320, \\ Taiwan \\ Fax: +886-3-463-8233Ｅ-mail: iccylian@ @aturn.yzu.edu.tw
}

*Corresponding author

\section{Wen-Shou Chou}

Department of Information Communication, College of Informatics, Yuan Ze University, 135 Yuan-Tung Rd., Chung-Li, Taoyuan, 320, Taiwan

Fax: +886-3-463-8277Ｅ-mail: cws@ saturn.yzu.edu.tw

\section{Yu-Ling Hsu}

College of General Studies, Yuan Ze University, 135 Yuan-Tung Rd., Chung-Li, Taoyuan, 320, Taiwan

Fax: +886-3-463-8233 E-mail: ulhsu@saturn.yzu.edu.tw

\section{Chien-Chien Yang}

LearningDigital.com, Taipei, Taiwan

E-mail: novia@learningdigital.com

\begin{abstract}
Under the national educational policy of Nine-Year Integrated Curriculum, elementary and junior high school teachers are expected to design their own instructional materials, and to teach their courses which could be linked to students' daily lives. The policy also allocates funding to create a variety of web-based instructional resource systems in order to assist these teachers in preparing their classes. Upon the basis of a user-centered design approach, this study is aimed at constructing a set of suggestions of planning, designing, and developing a web-based instructional resource system for the homeland education. This research team takes Nei-Li area in Taiwan as an example to develop such a system, and constructs a user-centered design model. The study results indicate that, unlike the traditional instructional design approach, the proposed model takes into account the user's needs, the capability of the project team, the resource availability for implementation, the national educational reform policy, the development of information technology industry, and the sociocultural context of a community at the initial phase. In addition, the development process is divided into two courses, one for contents
\end{abstract}


design while the other for system construction, both of which are implemented at the same time.

Keywords: User-centered design approach, homeland education, instructional resource system, website development.

Biographical notes: Chaoyun Liang is Professor of Department of Information Communication at Yuan Ze University in Taiwan. He currently serves as the Dean of Student Affairs.

Wen-Shou Chou is Associate Professor of Department of Information Communication at Yuan Ze University in Taiwan. He currently serves as the Chairman of the Department.

Yu-Ling Hsu is Assistant Professor of College of General Studies at Yuan Ze University in Taiwan. She currently serves as the Director of the Division of Counselling in the Office of Student Affairs.

Chien-Chien Yang is a Project Specialist in LearningDigital.com, Taipei, Taiwan.

\section{Introduction}

Under the educational policy of Nine-Year Integrated Curriculum in Taiwan ${ }^{1}$, the elementary and junior high school teachers are expected to be empowered to design their own instructional materials, and to teach their courses which could be linked to students' daily lives. The policy also allocates funding to assist school teachers in preparing their class materials. Many college research teams also put their efforts into creating various web-based instructional resource systems, but until now, few of these systems are embraced by the target school teachers. The materials in these systems are criticized as either being not-ready-to-use, or being unsuitable for children to learn because of their professionalized language. Faced with an explosion of information on the Internet, what motivates the researchers to conduct this study is to design an instructional resource system compatible with these teachers' needs and their capabilities.

1 The Nine-Year Integrated Curriculum is a Taiwan's educational policy, which is based on the humanistic ideology of "student-centered, holistic education" aiming at making all young learners develop ten basic life competencies. It purports to make fundamental changes in domestic practice of school curriculum and instruction. This curriculum comprises seven major domains of learning to offer students a complete knowledge map. 
To bridge the gap between the developer and the user of an interactive computer-based system such as an instructional resource website, the research team decides to adopt a user-centered design approach. This approach is claimed to be helpful to avoid the blind spot in a design project (Nielsen, 1994), because the potential users would be invited to join in designing and developing the product, and the users' needs thus could be taken into account (Jarrett, 2001). Through such a user participation process, the product usability would be enhanced, and the subjective satisfaction of users could be promoted (Riva, 2002).

On the basis of the user-centered design approach stated above, the purpose of this study is to construct a set of suggestions for planning, designing, and developing a web-based instructional resource system for the homeland education. The research team chooses Nei-Li area in Taiwan as an example to develop a homeland instructional resource website. While the system was constructed, the team analyzed the process and proposed the design guidelines. In addition to describing the current status and the difficulties to be faced with, in the end, this study also constructs a user-centered model for developing an instructional resource system of homeland education.

\section{Literature Review}

\subsection{Context}

In recent years, educational reforms worldwide have been developed with the goal of preparing citizens for the challenges of globalization. Globalization has been thought to require the broadening of people's perspectives beyond conventional geopolitical borders and cultures. Related reforms in Taiwan, according to Law (2004), has emphasized "generic and transnational skills, such as English proficiency and information technology, and developed tripartite frameworks for citizenship education at local, national, and global levels." At the same time, Taiwan has included local language, history, and identity into the school curriculum. Taiwan's nine-year compulsory education was first defined by the government in 1982. The Ministry of Education (MOE) put into practice the Education Reform Action Plan and adopted the principles of diversity and tolerance in re-building a learning environment in elementary and junior high schools that encourages academic excellence and respects the students' individual traits and potential.

One of the most important policies of this education reform is the establishment of Nine-Year Integrated Curriculum that empowers the local governments, schools and teachers to design the curriculum and teaching materials. The curriculum seeks to develop versatile citizens capable of responding to the challenges posed by globalization in the $21^{\text {st }}$ century. Under this policy, the MOE puts a special effort on the promotion of both digitalized education and homeland education. To bridge the digital gap between city schools and rural schools, the MOE supports college professors to create a variety of web-based instructional resource systems, and encourages college students to form digital volunteer groups to help kids in the rural areas use computers. In addition, homeland education becomes a required course for students to take in the elementary school. In this subject, students are encouraged to foster an interest in the natural and humanistic aspects of their immediate environment and to do studies to increase their knowledge of Taiwan's history and natural resources (Ministry of Education, 2007).

There are growing concerns regarding the applications and effects of integrating information technology into elementary education, especially the development of digital 
instructional resources (e.g. Adiguzel \& Akpinar, 2004; Easton \& Luppescu, 2004; Meyers, Shin, \& Nichols, 2008). In China, many teachers in elementary schools are investigating the network-based instructional model, and their students start to share Internet resources. The government not only pays attention to the development of instructional resources, but carries out modern distance education projects in village schools, for improving instructional quality and efficiency. Establishing excellent instructional resource systems is viewed as one of the most critical tasks nationwide. The digital instructional resources will be implemented in both student learning and teacher training for different regions in China (Wang, 2004).

After exploring the effect of using the homeland education website, Tseng, Chu, Liu, Li, \& Liao (2006) found that the connection between the homeland website and student's life experiences greatly promotes students' learning interests. Students also feel cheerful about the achievements they made, and become much more confident. According to the study, the interest resulted from the homeland education, in turn, would benefit the development of students' computer ability. Chang (2008) indicated that elementary school teachers often find it difficult to seek Taiwan historical resources, due to a lack of information-searching skills and the inadequate resources on the Web. Chang held that the designer of an instructional resource system must understand the environment and situation teachers faced with when they delivered instructional activities. How teachers seek and use the resource system and what problems teachers encounter when they transform the resources into the teaching materials, are also critical for the system designers to learn. Chang further indicated that the study of professionals' information-seeking behavior should take into special account both socio-cultural (such as information use environment) and eco-political aspects (such as educational policy), which are often neglected in the past (e.g., Leckie, Pettigrew, \& Sylvain, 1996).

\subsection{Instructional development}

The focus of this study is on instructional resource system rather than instructional material, but the development process is still the same. Until now, most researches about instructional resource system have concentrated on the development of technological part. Few of the studies pay attention to the most important issue: the process framework. This framework binds the relevant technical, human, organizational, and cultural considerations together and exerts the great influence on the innovative way of delivering instructional activities. Gustafson \& Branch (2002) suggested that developers need to acquire working knowledge of Instructional Development (ID) models. These models are the process framework put into practice. Gustafson et al. further indicated that instructional developers should always be sensitive to the situation encountered while applying the models.

Although the "ID model" concept came into prominence in the 1970s, it is still viewed as a primary tool for developing instructional materials, activities and systems at present. Most early ID models emphasized linear processes and logical steps, such as the five phases of Analysis, Design, Development, Implementation, and Evaluation (ADDIE) identified in the ADDIE model. Each of these steps describes actions that need to be taken, and works that need to be produced. Each will be inherently structured by the subtasks, "responding to each with completion as opposed of exploration ... implementation is viewed as simply getting the job done" as indicated by Hokanson (2006). These "lockstep in execution" models were criticized for lacking flexibility and being unrealistic. In the past decade, more approaches sought a flexible and context-oriented approach to get the job done as smoothly and as cost-effectively as possible (Kenny, 
Zhang, Schwier, \& Campbell, 2005; Liang \& Schwen, 1997; Reiser \& Dempsey, 2006; Twigg, 2003; Willis, 2000).

No matter a self-learning website for students or an instructional resource system for teachers, the design philosophy is still strongly dominated by a content-driven and knowledge production paradigm at present. Following more research devoted to this area, more recent studies emphasize the importance of navigation, collaboration, community, and cultural issues. As we have already experienced enormous challenges in coping with the overflow of Internet information, Brown (2006) argued for "constructivism out, navigationism in," especially when the knowledge economy is in its prime. In addition, the application of collaboration-driven technique has become one of the mostly discussed topics in the recent years. Studies like online discussion by Kanuka, Rourke, \& Laflamme (2006), the connection between community and learning by Chapman, Ramondt, \& Smiley (2005), collaboration technology by Dahl (2004), and cultural competence by Rogers, Graham, \& Mayes (2007), all have received much attention.

\subsection{Usability and user-centered design}

Usability is viewed as an evaluation method and a design process, which is aimed at promoting learnability, efficiency of use, memorability, few and noncatastrophic errors, and subjective satisfaction of a targeted product (e.g. Nielsen, 1994; Preece, 1995). In particular, web usability would need to take into consideration its information architecture, navigation design, iterative redesign cycle, user's personalized function, and heuristic evaluation (Pearrow, 2007). In their work "Usability for the web," Brinck, Gergle \& Wood (2002) indicated that a usability engineering for website includes six key processes: requirements analysis, conceptual design, mockups and prototypes, production, launch, and evaluation. The first process covers a full understanding of requirements of the target users, platforms, usage purposes, and necessary techniques. The conceptual design is a process to define the functions of the website. The functions defined are then transformed into a visual and interaction design in the process of mockups and prototypes. At the production phase, a complete website would be produced and assessed under a series of field tests. After all of the quality assurance tests are executed, the website will be launched, and ready for feedbacks from the target users.

Brinck et al. (2002) hold that some principles for making effective tradeoffs need to be taken into account in order to achieve the web usability: (1) the 80/20 rule for setting priorities (users usually spend $80 \%$ of their time using $20 \%$ of the website ); (2) design for manufacture needs, such as considerations on the capabilities of the production tools, the skills of the production staff, delivery limitations, and the cost of materials; and (3) design for evolution, that is, design needs to consider the likelihood of the website to evolve over a period of time. It is important to view usability as a pervasive element of the entire design process, Brinck et al. emphasized that, it will save time in the long run.

Preece (1995) indicated that a user-centered design is a participant design in which users are invited to participate in the entire design process. Preece formulated four design principles to engage users: (1) focus on users and their needs; (2) focus on the functions to satisfy the needs after completing the analyses of user tasks and task environment; (3) execute a formative evaluation in order to ensure that the system's functions meet the users' needs; and (4) use an iterative redesign cycle. Jarrett (2001) held that a user-centered design is an action which allows users to assist in the enhancement of usability. Lazar (2006) indicated that web usability is a matter of a usercentered design approach. She emphasized that a website must be designed with the user in mind in order to maximize the user experiences. "The user-centered development life 
cycle" is to ensure that the user needs should be the central issue of the website's design, from its conception to its implementation and management. Collecting requirements, designing pages, and performing usability testing, Lazar indicated, the designers keep in mind this focus, which would bring about a more effective design and more satisfied users.

The international standard ISO 13407 provides a guidance for achieving quality in use by incorporating user-centered design activities for interactive computer-based systems. There are four user-centered design activities that need to be conducted at the earliest stage of a project, including understanding and specifying the context of use, specifying the user and organizational requirements, producing design solutions, and evaluating designs against requirements. These activities are iterative in nature, and the process is evolving gradually until the objectives are satisfied (Jokela, Livari, Matero \& Karukka, 2003). A user-centered design values the feedback from users' experiences that could be described in terms of being useful, usable, desirable, findable, accessible, credible, and/or valuable (Morville, 2004).

In addition, McLoughlin \& Luca (2002) hold that a user centered approach could help to develop learners' team skills. Kravetz (2005) emphasized the importance of understanding users in order to build better products. Pearrow (2007) also confirms that a user-centered design is the central issue of web usability, which is based upon the user information. The user information should include: (1) finding the user's real needs; (2) revealing factors affecting the user's accessibility; (3) understanding which information the user wants to get from the web; (4) discovering the user's preference for the web design; (5) recognizing the user's preference for the system tools; and (6) comparing the relevant websites to understand things the user dislikes. Sharp, Rogers, and Preece (2007) further indicate that a user-centered design is a design activity for collaboration and communication. Basically, it is about developing interactive products that are easy, effective, and enjoyable to use-from the users' perspective.

\section{Method}

Research methodologies represent complex socio-historical evolutions within the social sciences. These inquiries emphasize dissimilar variations of data analysis as found in their conclusions gained from the research process. Academicians maintain humanity throughout the research process, it is almost impossible to escape the subjective experience, even for the most seasoned researchers. Unlike quantitative methodology with its explicit constructions and overarching frameworks, qualitative research includes a veritable cornucopia of philosophical stances and methods that are taken in relation by the research to each phenomenon. Unlike quantitative data, numeration is not a qualitative researcher's objective. Unlike quantitative research, the qualitative studies are not generalizable in the traditional sense, yet have redeeming qualities that set them above that requirement. By using a multi-indicator approach, qualitative methods can complement quantitative approach (Denzin \& Lincon, 2000; Patton, 2001).

The purpose of qualitative research is to offer a perspective of a situation. Qualitative studies are tools used in understanding and describing the world of human experience (Wallace \& Fleet, 1998). This study aims to construct a set of suggestions for planning, designing, and developing a web-based instructional resource system for the homeland education in Nei-Li area, Taiwan. In order to understand the selected area and the research-targeted topics, a series of in-depth interviews with users (the elementary and junior high school teachers) and experts of instructional resource system development 
were conducted from March 2007 through September 2007. By adopting a qualitative research approach, this study wishes to learn the "perspective of a situation" through the "tools used in understanding and describing the world of human experience".

The interviewees chosen in this study are all major participants of instructional resource system in Nei-Li area. The criterion set for user selection includes: those who are currently working as elementary and junior high school teachers in Nei-Li area, and who are familiar with the application of instructional resource system. Nine experienced teachers (interviewees coded as T1-T9) of social studies from the major schools in the area were identified by the local government to be interviewed. They are well-represented as teacher users to elaborate their needs and capabilities. The issues to be discussed include individual experiences of class teaching, of using instructional resource system, and of preparing teaching materials, and the understanding in the local affairs of Nei-Li area.

On the other hand, the experts selected to conduct interviews have the following common characteristics: those who have more than five years of experiences in designing and developing an instructional resource system, and who are familiar with class teaching in elementary and junior high schools. Ten experts (interviewees coded as E1-E10) from higher education establishments, research institutes, and information industry were selected as interviewees. These experts were nominated by the teacher users mentioned above, and all have close helping relationships with them. They are well-represented as developers to share their experience and comments. The issues to be discussed include individual practical experiences of planning, designing, and evaluating instructional resource systems.

At the same time, the research team takes Nei-Li area as an example and develops a web-based instructional resource system for the homeland education. As the iterative redesign cycle of the system evolves, the team then concludes and proposes a set of suggestions for planning, designing, and developing such a system based upon the results of the interviews. These experts and the school teachers mentioned above are also invited to participate in the design process of the web-based system this study constructed, and continually provide their opinions and suggestions.

\section{Discussion}

\subsection{Critical factors to be considered in the front-end analysis}

Since the research team adopts a user-centered design approach that allows the teacher users and the experts to participate throughout the whole process of constructing the system, the participants are pretty satisfied with the performance of the prototype and take the initiatives to express their willing to join the next development project. Following the evolving design process, the research team learns that the user's needs, the capability of the project team, and the resources availability for implementation are still important factors for the system development. In addition, the team discovers that the national educational reform policy, the development of information technology industry, and the socio-cultural context of a community have a great impact on the construction of instructional resource system for homeland education. In particular, these later three factors are seldom discussed in the literature regarding instructional resources development. 
The user's needs, the capability of the project team, and the resources availability for implementation are critical factors often mentioned in the relevant literature. From the aspect of the user's needs, a lack of existing instructional resources is the major problem, because people in Nei-Li area are devoid of a sense of community. This phenomenon leads to two results: (1) the teaching materials of homeland education in the social study classes are difficult to collect; (2) the students still do not have a concrete idea about the socio-cultural background of this area after the class (by T1-T4, T6-T8).

From the aspect of the capability of the project team, the capabilities of handling the entire construction process including analysis, design, development, production, and evaluation are demanded as can be observed in the related literature. The team finds that the capabilities of operating the system and providing consequent services are also critical, but seldom mentioned before (by T2, T4-T6, T9).

From the aspect of the resources availability for implementation, human resources, facilities, time, and budget are still crucial as can be reviewed in the relevant literature. The research team further learns that the resources of maintaining the contents in the system, of promoting the usage of the system, and of innovating the user services are also important tasks to gain a sustainable system operation (by T1-T3, T5, T7-T9).

The newly emerging factors which would affect the construction of instructional resource system for homeland education include the national educational reform policy, the development of information technology industry, and the socio-cultural context of a community. From the aspect of the national educational reform policy, the research team realizes that any nationwide educational policy, such as Nine-Year Integrated Curriculum and the integration of information technology into subject teaching, has its profound impact (by T3, T6, T7-T9).

From the aspect of the development of information technology industry, the policy of promoting information education would benefit greatly from the intense development of information technology industry in Taiwan. This intense development, however, usually leads to an over-emphasis on the hi-tech applications, rather than links class teaching back to the essence of education (by T2, T4-T5, T9).

In addition, the economic development of a township would affect the cohesion of a community which, in turn, would result in people relocation. The Nei-Li area is such a case of suffering from people drain and the loss of cultural heritage. The factor of the socio-cultural context of a community also has a great deal of effect on the construction of instructional resource system for homeland education (by T1-T4, T6-T8).

\subsection{Suggestions for planning and designing an instructional resource system}

After a series of intense interviews, the research team comes up with a set of proposed suggestions for planning an instructional resource system for homeland education. These suggestions are taking a user-centered design approach into account. They are summarized as follows:

(1) Clarifying the real problems encountered at a teaching site and the plan for resolving these target problems (by T1-T9, E1, E3, E10);

(2) Taking into account critical factors such as the user's needs, the capability of the project team, the resources availability for implementation, the national educational reform policy, the development of information technology industry, and the sociocultural context of a community in the front-end analysis (by T1-T9, E1-E2, E4E10); 
(3) Analyzing, in particular, the users' needs and capabilities at the same time, and then integrating theses analyses into the following usability enhancement process (by T4, T8, E1-E3, E6-E8);

(4) Planning a formative and summative evaluation for collecting the user's performance and degree of satisfaction, and continually collecting the user's newly emerging needs as well (by T8, E2-E7, E9);

(5) Clearly defining usability through a rapid prototyping process, and planning for iterative testing for the system functions, in order to avoid unnecessary errors (by T8, E1, E4-E8, E9-E10);

(6) Checking carefully on the contents and the sources collected in the system, and paying special attention to the copyright issues (by T1, T4-T5, T7, E2-E4, E7-E9);

(7) Registering the resource system onto the major portals of search engines, and developing a thorough plan for a long-term operation of the system (by T2-T4, T9, E4-E10).

In addition, the other set of suggestions for designing and developing an instructional resource system is also proposed. Based on the use of a user-centered design approach, these suggestions can be summarized as follows:

(1) Clearly defining the purpose of each phase for the system usage, and then designing accordingly and communicating constantly (by T3, T9, E1-E6, E8-E10);

(2) Putting ready-to-use materials into the resource system, and ensuring that these materials be closely related to the school curriculum (by T1-T9, E4-E7, E9-E10);

(3) Getting a deep understanding of the situation and the context in which the teachers use the resource system, and simulating the process of preparing teaching materials to obtain an empathetic understanding of the difficulties of transforming the information in the system into their teaching materials (by T1-T3, T5, T7, E2-E5, $\mathrm{E} 8, \mathrm{E} 10)$;

(4) Providing the users an effective search engine and navigation tools in order to assist in preparing instructional tasks, and enhancing the contents design and developing necessary functions for the system (by T1, T4, T8-T9, E2-E6, E8-E9);

(5) Strengthening the user feedback mechanism to ensure that the users gain sufficient information and appropriate consultation, which allow the users to discuss, to share, to think, and to response (by T2-T7, E3-E7, E10);

(6) Clarifying the conflicting interests among the users, the system-owned organization, and the stakeholders, as well as ironing out the potential controversy among them (by T1, T3, E2, E3, E7-E10);

(7) Giving space for the system to grow, that is, planning to make the instructional resources and the system architecture extensible and easy to update and upgrade (by T2, T4, E1-E10);

(8) Developing the system for the purpose of long-term operation to achieve the goal of assisting users in teaching; that is, distributing the necessary resources not only to the phases of analysis, design, production, and evaluation, but also to the aspects of maintenance, operation, service, and continual improvement (by T3, E1, E4-E8, E10). 
The study results reveal that the current mode of instructional resource system development in Taiwan relies heavily on school teachers themselves. However, the teachers could not participate in the design process completely because of their insufficient expertise of system development and their heavy teaching loads. Therefore, these teachers would usually hire a digital media design team to help them in constructing the resource system. How to crystallize the teacher's needs, and make them in step with digital media designers thus becomes a critical issue for us to deal with. On the basis of the findings of this study, the research team identifies a need to construct a development model for both teacher users and digital media designers. This model would offer a framework that ensures the development process more feasible. It would also provide teachers and designers working knowledge to team up in a collaborative mode.

\section{Conclusion}

To conclude this study, the research team proposes a user-centered design model to develop an instructional resource system for homeland education in Taiwan. As mentioned earlier, due to their insufficient expertise of system construction and their heavy loads, Taiwan's school teachers usually hire digital media designers to assist them in developing the instructional resource system. Therefore, unlike the traditional ID model in which the component tasks are usually organized in a linear sequence, the proposed model is divided into two sides, one side representing the content of instructional resources and teacher users, and the other side representing the resource system and digital media designers. In other words, the development process consists of two courses, one for contents design handled by the teacher team, the other for system construction managed by the digital media designers, with both courses working closely with each other and put into practice at the same time.

Although the major considerations and duties are different, the process tasks on both courses still could be classified into the same categories. Both courses are influenced greatly by factors of national education reform, district and school information education policy, and development of information technology industry. They roughly follow six stages of process tasks including: clarification, analysis, design, development, implementation, and evaluation. Unlike the traditional ID model which usually begins with learner and task analyses, the proposed model is initiated from the stage of clarification, due to a need to narrow the gap between teachers and media designers. At the content side, the stage of clarification takes into account socio-cultural context of a community, target user, and needs/problems in the teaching site. On the other hand, the same stage in the system side takes into account the user's ability to apply the information technology, the capability of the project team, and the resources availability for implementation.

According to the findings of this study, each side would put different focuses on every stage of construction. At the stage of analysis, the content side would make effort to analyze users' needs, instructional contents, teaching themes, and the relationship between contents and curriculum, while the system side would examine the system architecture, information flow, navigation tools, and related hardware/software issues. At the stage of design, the content side puts its focus on a variety of design issues regarding instructional materials, teaching methods, context, interaction, and on assessment of the contents developed, while the system side concentrates on the aspects of layout design, interface design, and prototype assessment. 
Furthermore, at the stage of development, the content side would implement the tasks of content authoring, transformation, and production. At the same time, the system side would put action on web page production, database building, programming, system integration, and even online testing. At the stage of implementation, the content side would carry out field trial and keep expanding the instructional resources. Concurrently, the activities of online operation, system promotion, and system maintenance would take place in the system side. The major tasks to be performed at the stage of evaluation include instructional evaluation and usability evaluation. All the stages stated above are carried out either sequentially or concurrently, as diverse situations continually evolve.

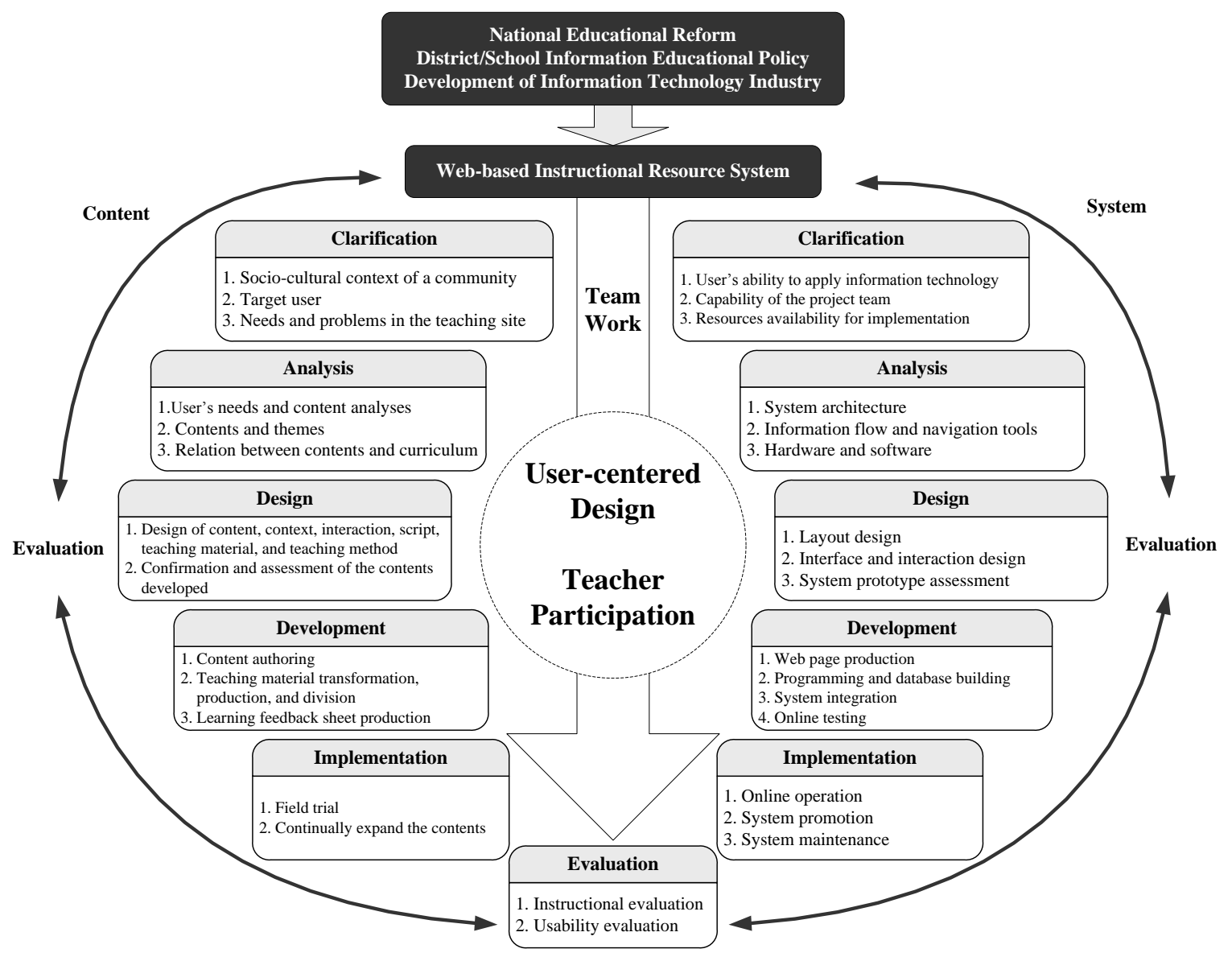

Figure 1. The model of a user-centered design for developing an instructional resource system for homeland education

Unlike the lock-step nature of traditional ID models which has long been criticized as overly rigid and unrealistic, the proposed model is reality-based, iterative in nature, and puts users' needs as the central concern in the whole development process. By means of the user-centered design approach, the teacher users and media designers would work closely to clearly define usability through a rapid prototyping process in order to avoid unnecessary errors. The iterative design process would strengthen user feedback 
mechanism which, in turn, ensures the users gain sufficient information and reach appropriate decisions. In addition, this model is descriptive in nature and refers to no specific technical procedures. It operates within the architectural structure of the interlacing network for the purpose of long-term operation to achieve the goal of assist teacher users in teaching. This architectural structure also implies that the distribution of the necessary resources not only to the phases of analysis, design, production, and evaluation, but also to the aspects of maintenance, operation, service, and continual improvement (see the figure 1).

With the restriction of the research energy, this study puts focus only on the instructional resource system with the subject of homeland education. The district for this study is narrowed down to Nei-Li area in Taiwan, and the users are restricted to the teachers from the elementary and junior high schools in this area. As suggested by the team, the future study could select different subjects and/or focus on different areas. The methodology used for this kind of research could be more diversified, and the research target may be expanded to students as well. In addition, to put the existing system into the real-world trial to evaluate its performance is another valuable line of the research, and equally valuable are inquires into the information-related educational reform policy on either national or local level.

\section{Acknowledgments}

The support of Taiwan's National Science Council and the assistance from the graduate assistant Chien-Chien Yang are gratefully acknowledged. The current research is part of the research project number (NSC95-2754-E-155-011-URD) of Taiwan's National Science Council.

\section{References}

1 Adiguzel, T. \& Akpinar, Y. (2004). Improving school children's mathematical word problem solving skills through computer-based multiple representations. ERIC: ED485024.

2 Brinck, T., Gergle, D., \& Wood, S. D. (2002). Usability for the web: Designing websites that work. San Diego, CA: Academic Press.

3 Chang, S. L. (2008). An investigation into information needs and information seeking behavior of elementary and middle school teachers teaching indigenous courses (in Chinese). Journal of Library and Information Studies, 4(1/2), 49-76.

4 Chapman, C., Ramondt, L., \& Smiley, G. (2005). Strong community, deep learning: Exploring the link. Innovations in Education \& Teaching International, 42(3), 217-230.

5 Dahl, J. (2004). Focus on collaboration, and the technology will follow. Distance Education Report, 8(15), 5-6.

6 Denzin, N. K. \& Lincon, Y. S. (2000). Hankbook of qualitative research (2 ${ }^{\text {nd }}$ ed.). New York: Sage.

7 Easton, J. Q. \& Luppescu, S. (2004). Teacher and principal responses to the grow network. Chicago, IL: Consortium on Chicago School Research

8 Gustafson, K. L, \& Branch, R. (2002). Survey of instructional development models ( $4^{\text {th }}$ ed.). Syracuse University, NY

9 Hokanson, H. M. (2006). A role based model of instructional design practice. Retrieved September 15, 2008, from the World Wide Web: https://wiki.umn.edu/view/ARECpaper/StartingWriting 
10 Kanuka, H., Rourke, L., \& Laflamme, E. (2006). The influence of instructional methods on the quality of online discussion. British Journal of Educational Technology. Retrieved September 10, 2008 from the World Wide Web: http://www.blackwell-synergy.com/doi/abs/10.1111/j.1467-

11 Kenny, R. F., Zhang, Z., Schwier, R. A., \& Campbell, K. (2005). A review of what instructional designers do: Questions answered and questions not asked. Canadian Journal of Learning and Technology, 31(1), 9-26.

12 Kravetz, A. F. (2005). The role of user centered design process in understanding you users. Retrieved September 15, 2008, from the World Wide Web: http://iadlc.nul.nagoya-u.ac.jp/archives/IADLC2005/kravetz.pdf

13 Jarrett, C. (2001, May). Usability means User-centered design. Paper presented at the the 48th Annual Conference of the Society for Technical Communication, Chicago, U.S.A. Retrieved August 30, 2008, from the World Wide Web: http://www.stc.org/confproceed/2001/PDFs/STC48-000127.PDF

14 Jokela, T., Livari, N., Matero, J., \& Karukka, M. (2003). The standard of usercentered design and the standard definition of usability: Analyzing ISO 13407 against ISO 9241-11. ACM International Conference Proceeding Series, 46, 53-60. Retrieved August 30, 2008, from the World Wide Web: http://delivery.acm.org/10.1145/950000/944525/p53-

jokela.pdf?key $1=944525 \&$ key $2=6483615711 \& \mathrm{coll}=\& \mathrm{dl}=\mathrm{acm} \& \mathrm{CFID}=15151515 \&$ CFTOKEN=6184618

15 Law, W. (2004). Globalization and citizenship education in Hong Kong and Taiwan. Comparative Education Review, 48(3), 253-273.

16 Lazar, J. (2006). Web usability: A user-centered design approach. Boston, MA: Addison Wesley.

17 Leckie, G.J., Pettigrew, K.E., \& Sylvain, C. (1996). Modeling the information seeking of professionals: A general model derived from research on engineers, health care professionals, and lawyers. Library Quarterly, 66(2), 161-193.

18 Liang, C. \& Schwen, T. (1997). A Framework for Instructional Development in Corporate Education, Educational Technology, 37(4), 42-45.

19 McLoughlin, C., \& Luca, J. (2002). A learner centered approach to developing team skills through web based learning and assessment. British Journal of Educational Technology, 33(5), 571-582.

20 Meyers, J. L., Shin, D., \& Nichols, P. (2008). Integrated assessment and instructional resource system: A white paper from the assessment \& information group of Pearson. Pearson Education Inc. Retrieved September 10, 2008, from the World Wide Web:

http://www-stage.pearsonperspective.com/index_whitepapers.htm

21 Ministry of Education (2007). Compulsory education: Helping kids score goals. Education ROC 2007, 15-20. Retrieved September 15, 2008, from the World Wide Web: http://english.moe.gov.tw/public/Attachment/7111218443971.pdf

22 Morville, P. (2004). User experience design. Retrieved August 25, 2008, from the World Wide Web: http://semanticstudios.com/publications/semantics/000029.php

23 Nielsen, J. (1994). Usability engineering ( $2^{\text {nd }}$ ed.). MA: Margan Kaufmann.

24 Patton, M. Q. (2001). Qualitative research and evaluation methods ( ${ }^{\text {rd }} \mathrm{ed}$.). New York: Sage.

25 Preece, J. (1995). A guide to usability: Human factors in computing. Wokingham: Addison-Wesley.

26 Pearrow, M. (2007). Web usability handbook ( $2^{\text {nd }}$ ed.). Boston, MA: Thomson.

27 Reiser, R. \& Dempsey, J. V. (2006). Trends and issues in instructional design and 
technology ( $2^{\text {nd }}$ ed.). NY: Prentice Hall.

28 Riva, G. (2002). Web usability revisited: A situated approach. PsychNology Journal, 1(1), 18-27. Retrieved December 30, 2007, from the World Wide Web: http://www.psychnology.org/File/PSYCHNOLOGY_JOURNAL_1_1_RIVA.pdf

29 Rogers, P. C., Graham, C. R. \& Mayes, C. T. (2007). Cultural competence and instructional design: Exploration research into the delivery of online instruction cross-culturally. Educational Technology Research and Development, 55(2), $197-$ 217.

30 Sharp, H., Rogers, Y., \& Preece, J. (2007). Interaction design: Beyond humancomputer interaction. NY: John Wiley and Sons.

31 Tseng, K., Chu, Y., Liu, Y., Li, Y., \& Liao, C. (2006). The effect of application computer in homeland education of students. Proceedings of the $5^{\text {th }}$ WSEAS International Conference on Applied Computer Science (pp. 17-21), Hangzhou, China.

32 Twigg, C.A. (2003). Improving learning and reducing costs: New models for online learning. EDUCAUSE Review, 38(5), 29-38.

33 Wallace, D. P. \& Fleet, C. V. (1998). Qualitative research and the editorial tradition: A mixed metaphor. Library Trends, 46(4), 752-769.

34 Wang, R. (2004). The development and application of e-learning in China. Asia and the Pacific Seminar-Workshop on Educational Technology.

35 Willis, J. (2000). The maturing of constructivist instructional design: Some basic principles that can guide practice. Educational Technology, 40(1), 5-16. 